\title{
The influence of content and non-content cues of tourism information quality on the creation of destination image in social media: A study of Khyber Pakhtunkhwa, Pakistan
}

\author{
Danish Ali | Liu Xiaoying* \\ School of Tourism Management, Zhengzhou University, Henan, China. \\ *Correspondence Emails: liu.xiaoying@zzu.edu.cn | zhengzhoulxy@163.com
}

\begin{abstract}
This research examines the Content Cues (CC) and Non-Content Cues (NCC) of tourism Information Quality (IQ) in social media (e.g., Instagram, Twitter, Facebook) and its influence on creating Destination Image (DES) components i.e., "cognitive image (COG), affective image (AF), conative image (CON)" in the scope of Khyber Pakhtunkhwa (KP), Pakistan. We distributed 500 questionnaires at various tourist destinations, and 446 complete questionnaires were returned and use for further analysis. We use the Confirmatory Factor Analysis (CFA) and Structural Equation Modelling (SEM) to get the research outcomes. Our outcome suggests that CC and NCC of tourism IQ are significantly related to the $\mathrm{COG}$ and $\mathrm{AF}$, which leads to the CON. Our finding also identified the relationship between CC and NCC with $\mathrm{CON}$ through the mediation role of $\mathrm{COG}$ and $\mathrm{AF}$, which were positive and significant. This research extends the insight of tourism IQ in social media, precisely the contextual dimension of IQ, by providing empirical evidence. This research also helps the KP Destination Marketing Organizations (DMO's) to develop their marketing strategies to encourage more visitors by utilizing Social Media (SM) platforms to their destinations.
\end{abstract}

Article History

Received:

March 1, 2021

Last Revised:

May 14, 2021

Accepted:

May 15, 2021

Published: June 5, 2021

Keywords: promoting tourism, destination image, destination marketing, information processing, Confirmatory Factor Analysis, Structural Equation Modelling.

How to Cite: Ali, D. \& Xiaoying, L. (2021). The influence of content and non-content cues of tourism information quality on the creation of destination image in social media: A study of Khyber Pakhtunkhwa, Pakistan. Liberal Arts and Social Sciences International Journal (LASSIJ), 5(1), 245265. https://doi.org/10.47264/idea.lassij/5.1.17

Publisher's Note: IDEA PUBLISHERS (IDEA Journals Group) stands neutral with regard to the jurisdictional claims in the published maps and the institutional affiliations.

Copyright: (C) 2021 The Author(s), published by IDEA PUBLISHERS (IDEA Journals Group). This is an Open Access article published under the Creative Commons Attribution-NonCommercial 4.0 International License (http://creativecommons.org/licenses/by-nc/4.0/) 


\section{Introduction}

Recently, tourism has emerged as a countable industry globally, which strongly influences the nation's economy. Furthermore, it is also relatable to various other sectors, including advertising, promotions, product endorsement, sponsorships, and corporate organization (Kanwel et al., 2019). Along with the rise of globalization, the tourism's economic importance is essential for creating a tourist destination, provided the continual demand for information about the destination. However, the speed of access to information and rapid technology development is progressively altering user behaviour, which directly affects the tourist destination's business strategies.

Information plays a vital role in creating a DES (Stepchenkova \& Morrison, 2008; Tasci \& Gartner, 2007). The quality of SM information is among the elements affecting DES creation (Kim et al., 2017). An image of the destination is an important feature affecting the tourist's decision about preference and revisit to the destination (Chaulagain et al., 2019). The tourism industry is among the most substantial influences on using new communication technologies (Buhalis \& Law, 2008; Hughes et al., 2010). Thus, overall tourism destinations are competing to attract more potential tourists. Having the internet and using SM effectively are the essential factors in providing high-quality information, attracting travellers, and enhancing the DES.

The penetration of SM is ever-increasing globally. The total population in the world is 7.83 billion. Simultaneously, 4.66 billion are internet users, and 4.20 billion are active SM users, $53.6 \%$ of the total world population. The total population of Pakistan is 22.3 million, while 61.34 million are internet users and 46.00 million are SM users (we are social 2021). Facebook, Instagram, and Twitter are the world popular social network and in Pakistan. SM also profoundly influences how people are looking and published knowledge and decide their destinations. Therefore, researchers concur that SM is an essential source of travel knowledge regarding the destination (Zeng \& Gerritsen, 2014).

The literature about DES creation is well known (Baloglu \& Mccleary, 1999; Marine-Roig \& Clavé, 2016), and SM in tourism is quite prevalent (Leung et al., 2013). Notably, the researchers interest has risen recently, as both ideas have been introduced together (Hays et al., 2013). Most research has focused on how destinations utilize SM platforms to enhance their image (Usakli et al., 2017), or how tourists through SM sites become co-creators of the DES (Heras-Pedrosa et al., 2020), and other studies focus on overall or few dimensions of SM IQ and its influence on image creation (Kim et al., 2017; Nunthiphatprueksa, 2017). However, to the present, there has been little research work that has concentrated on a single dimension of IQ in SM and its association with the creation of DES (particularly in Pakistan).

Taking into consideration (Kim et al., 2017) suggestions for further investigation by using different SM channels (e.g., Instagram, Facebook, Twitter) from other regions. The primary purpose of this research work is to evaluate relationships among contextual tourism IQ from (Wang \& Strong, 1996), which were classified as CC and NCC based on information processing heuristic and systematic model (Chaiken, 1980), in social media (e.g., Instagram, Facebook, Twitter) as well as "Cognitive, Affective, Conative" destination image creation theory by (Gartner, 1994). According to (Kim et al., 2017), the contextual factor is more critical in influencing DES than other IQ dimensions. This study answers the following question 1. what tourism IQ element "CC and NCC" in SM influence DES components? and 2. how these elements influence the CON or (behavioural intention of tourist)? 
This research examines the $\mathrm{CC}$ and $\mathrm{NCC}$ in SM relationship with CON via the mediating role of the COG and AF. Most prior research concentrated on the COG and AF role for visitors' behavioural intention (Kim \& Yoon, 2003; San Martín \& Del Bosque, 2008; Yüksel \& Akgül, 2007). In almost all studies, DES components have been examined, and scholars only concentrated on COG and AF without a CON (Zhang et al., 2014). Recent research by (Kim et al., 2017) examined the contextual IQ and representational IQ relationship with the COG and AF, excluding its relation with the CON. The previous study suggests that the CON has an equal conception stage with cognitive and affective DESs (Woosnam et al., 2020). CON is linked with a person's action and behaviour; therefore, we contend that high-quality information will influence the individual behaviour to share the positive word of mouth about the destination and will recommend to others. In tourism literature, scholars have mostly linked the conative aspect with revisit or loyalty (Gnoth et al., 2009; Li et al., 2010); loyalty/revisit or $(\mathrm{CON})$ is a highly complex factor for DMO's because it is less expansive, more comfortable use keep existing visitors than to attract a new visitors. Therefore, this research will fill this gap to investigate the IQ association with $\mathrm{CON}$ via the mediating role of $\mathrm{COG}$ and $\mathrm{AF}$.

Based on the relevant literature study, we find that this type of study mainly concentrated on the western context. In contrast, it primarily focuses on East Asia when literature focuses on the Asian perspective (Stepchenkova \& Mills, 2010). The area of KP, Pakistan varies considerably from countries in East Asia. The south Asian countries have different cultures, traditions, and tourism attractions from east Asia regions. The selection of KP as a context for conducting this study adds to the literature IQ in SM and DES creation. The KP is among Pakistan leading tourists' destinations and potential for tourism. The KP is the country's treasure chest of tourism and is rapidly becoming a desired destination for domestic and international tourists. It is well-populated with historical, religious, and natural resources shaped by the Hindukush and Himalayas mountains, offering spectacular alpine landscapes, iconic wildlife, majestic forests, and numerous glacial lakes.

\section{Theoretical framework}

\subsection{Social media in the context of tourism}

SM in tourism is becoming important day by day. The usage of SM in consumers' daily lives dramatically change the tourism business and is crucial for emerging tourism firms. Since the internet has innovated communications in tourism and will continue to reform, researchers have gained considerable attention towards this field. In 1999, a supply-driven network (Web 1.0) was established and designed to be a read-only platform that allowed tourism service providers to create visual pamphlets (Fuchs et al., 2010; Noti, 2013). Web 2.0 has established in 2005 with communicative channels (Minić, n.d.). Web 2.0 offers a better communication experience from both sides (Eftekhari et al., 2010). So far, SM has become a valuable tool for destination marketing (Berhanu \& Raj, 2020; Kanwel et al., 2019). The extensive range of SM platforms has made it challenging to reach the SM standard definition (Kaplan \& Haenlein, 2010). SM is defined as "a group of web-based applications that draw on the ideology and technical foundations of Web 2.0 it enables user-generated content to create and distribute.

Social networks are now the most reliable information sources on company products from a consumer perspective (Kim et al., 2017). SM became a crucial part of marketing and corporate development in the $21^{\text {st }}$ century, significantly changing how firms communicate and advertise to their target market (Bosio et al., 2018). More specifically, scholars have found that SM is a 
decisive element to boost tourism destination products and services (Kanwel et al., 2019). Many travel companies using SM supply visitors with adequate knowledge about a destination (Söderlund \& Rosengren, 2007). It is the most effective way to communicate and transmitting information with a broader audience (Hasan, 2015). SM also cover advertising costs to attract more tourists by providing better facilities and adequate information (Hudson et al., 2015).

SM's increasing relevance in tourism has now become a growing area of study. Zeng and Gerritsen (2014) published a review by focusing on 279 papers; the author says that SM plays a vital role in the tourism sector in many aspects, mainly looking for travel information and decision-making. SM is a crucial element in tourism, as tourism is information-oriented and SM is widely available with information; thus, cooperation is mutually significant to encourage visitors to use SM as a guide for travel (Fatanti \& Suyadnya, 2015; Gretzel et al., 2000). Tourism depends on verbal communication, such as opinions, ideas, and comments on social networks (e.g., Instagram, Facebook, Twitter) that allow users to share feedback and suggestions (Kazak, 2016). By considering the online review, users can better understand the destination's services and products (Leung et al., 2013).

The literature shows SM's role in travel information; however, the essential element of SM travel knowledge is unknown. Little has been acknowledged about which aspect of tourism IQ in SM is most significant (Kim et al., 2017). This research aims to find a crucial element of contextual IQ classified as CC and NCC and measure their influences on decision-making over DES to know the importance of tourism-related information in SM.

\subsection{Tourism information quality in social media platforms}

Recently, the awareness and the effectiveness of SM have grown, but little has been identified about its efficient use in the tourism sector. Hence, the tourism information feature in SM will be examined in this study and its effects on the DES creation. Although SM is a valuable source of information, data quality judgment has emerged because dynamic and irregular information is subjected to users (Arazy \& Kopak, 2011). To make the best use of quality of information, the focus should be on the consumer's perspective rather than on the data perspective (Kim et al., 2017). It is also supported by various literature, Information Quality (IQ) measured by consumers, not by the system itself, influences the purchase of products (Kahn et al., 2002). IQ in SM is defined as the appropriateness of knowledge for a specific user's particular task for a particular idea (Emamjome et al., 2013; Hernández-Ortega et al., 2020).

The dimension of IQ has typically been identified as different dimensional concepts rather than a one-dimensional concept. IQ has been divided into four distinct areas: intrinsic IQ, contextual IQ, representation IQ, accessibility IQ (Wang \& Strong, 1996). It has been observed that different dimensions of IQ are used according to context and intent. Intrinsic IQ is the extent to which the knowledge is accurate, believable, trustworthy, and presented by a creditable source. Contextual $I Q$ is the extent to which a report adds value and is relevant, timely, complete, and sufficient. Representational $I Q$ covers the consistency and concise representation of information. Accessibility $I Q$ concentrates on how information can be accessed and procured.

These components have known from (Wang \& Strong, 1996) IQ framework can also be reclassified as content (e.g., systematic) and Non-Content (e.g., heuristic) based on the information processing heuristic and systematic model proposed by (Chaiken, 1980). Heuristic 
Systematic Model (HSM) is commonly used to describe how an individual gets and processes the information. Systematic processing requires a detailed description and systematic assessment of appropriate information. In contrast, heuristic data processing requires little cognitive effort to reach conclusions based on the minimal effort principle of the model (HSM), relying on heuristics or NCC (Chen \& Chaiken, 1999). As (Wang \& Strong, 1996) IQ framework does, this HSM can also provide a helpful framework for explaining users' behaviour on the web (Zhang et al., 2014); thus, heuristic and systematic model can also be applied to this study. This research study uses a single IQ dimension in different SM platforms (e.g., Instagram, Facebook, Twitter). This research frequently focuses on a contextual aspect of IQ, which includes relevancy, timeliness, completeness, interestingness, and value-added is classified as "Content Cues." Quantity of information is classified as "non- Content Cues." When users receive and process tourism information on SM, they will usually consider both content and non-content IQ.

Consequently, both Content and Non-Content information is commonly considered in SM as customers receive and process travel information. A recent survey selected two dimensions of IQ, contextual and representation in Chinese social media Sina Weibo users, and analyzed Gyeonggi's destination (South Korea) (Kim et al., 2017). However, no research has found the present, focusing on one dimension of IQ (particularly in KP) and its association with DES components. Therefore, this research will fill this gap as it focuses on one dimension of IQ: contextual IQ and its influence on DES creation. The contextual IQ element illustrates the requirements of the given task. High-quality knowledge must be contextually accurate and should be specified for the objective. Therefore, we assume that the contextual IQ aspect explains better the different information criteria that visitors need to discover, interpret, classify, and analyze information on SM. Thus, this study seeks to investigate how the CC and NCC of tourism IQ in SM influence DES creation components.

\subsection{Destination image formation}

DES was well studied from the early 1970 's which shows that the DES substantially influence tourist selection (Kanwel et al., 2019; Li et al., 2015). The DES is also an essential factor determining the traveller's decision, preferences, satisfaction, and revisit to the destination (Chaulagain et al., 2019). DES is defined as collecting beliefs, ideas, and experiences about a destination (Kanwel et al., 2019). The Image of the Destination plays two vital behavioural roles: to influence the selection process as well as influence post-decision intentions, which includes destination experience, valuation, and revisit intentions in the future (Lee et al., 2005). The DES is usually understood as combining perception and experience based on knowledge from different sources (Gartner, 1994; Stylidis et al., 2021). The destination's image is an interaction process associated with opinions, beliefs, and even future intentions (Tasci et al., 2007). As various studies showed, over the last period, the image has a key area for researchers. However, other studies have provided theoretical aspects over time (Wang \& Hsu, 2010). Hunt (1975) highlighted that DES is an effective way to increase visitors' numbers and affect visitors' choice and decision. The DES formation process has three components, cognitive (Perceptual), affective (Feelings), and conative (Behavioural) (Gartner, 1994).

Based on the literature on SM and the DES, we believe that SM is a viable information source in promoting the tourist destinations. The creation of DES and SM is an exciting area for the researchers which is still underplayed. Many of the existing research on SM association with DES are theoretical studies (Ghazali \& Cai, 2014; Tham et al., 2013), or concentrating on COG 
and AF excluding (CON) behavioural (Zhang et al., 2014). Besides, majority of the studies have been carried in the western context. According to Pike (2002), 142 published papers from 1973 to 2000 show that most studies relate to the Western context. In contrast, the literature focuses on eastern Asia when it focuses on the Asian perspective (Stepchenkova \& Mills, 2010). Therefore, we assume that our study helps to fill this gap, highlighting the study's significance in Pakistan in general and the KP in particular.

\section{Hypothesis development}

\subsection{The relation between cognitive/affective image and content, non-content cues of tourism information quality}

The literature shows that in DES creation and E-information processing for consumers, information plays a vital role (Stepchenkova \& Morrison, 2008; Tasci \& Gartner, 2007). COG is not only formed by commercial tourism information but also by the social impact, including friends and relatives (Fakeye \& Crompton, 1991). Other studies have found that the quantity of information and information sources is crucial for the user's DES formation (Kim et al., 2017). Secondly, previous studies on information processing HSM (Chaiken, 1980) have also shown that users' information processing in a different way has significantly influenced both Content and Non-Content factors in a different online context (Wirth et al., 2007). Systematic (Content) and Heuristic (non-content) information in online reviews of the product are significantly associated with using of Information by product developers (Yang, 2015). We use two sources, information processing based on Heuristic Systematic Model (Chaiken, 1980), and DES formation (Gartner, 1994) to contend, the relations between aspects of contextual tourism IQ, which were classified as "CC and NCC" and DES formation components.

The quantity of information classified as NCC in our research model is referred to as the extent to which the quantity of information available in SM is appropriate in quantity. The empirical evidence provided by Baloglu \& Mccleary (1999) that the information in appropriate quantity significantly influences the COG. Besides, Gartner (1994) also argues that the information quantity obtained by a person affects the creation of the cognitive dimension, not the affective component. Therefore, we say that the information quantity is only significantly related to the cognitive dimension. There are some reasons; firstly, the association among the quantity of information and COG, an adequate quantity of information presented in SM such as information regarding accommodation, restaurants, local attractions, culture, and other information will help visitors from the perceptual sense (cognitive) understand what they can do at the destination.

Consequently, an adequate quantity of information about a destination in SM is not guaranteed to influence a visitor's feelings or emotions (AF). In contrast, lengthy and well-defined textbased knowledge may not directly associate with AF. From these perspectives, we proposed Hypothesis 3. The DES creation and heuristic and systematic model of information processing can be applied to create an overall theoretical framework that different CC and NCC of SM tourism knowledge can influence the way consumers shape the DES. Therefore, three hypotheses are proposed as follows:

Hypothesis 1: CC of tourism information in SM has a significant influence on COG. Hypothesis 2: CC of tourism information in SM has a significant influence on AF. Hypothesis 3: NCC of tourism information in SM has a significant influence on COG. 


\subsection{The relationship between cognitive, affective, and conative destination image}

The effect and cognition are an intellectual reaction to environmental factors, creating an interactive and dynamic network (Tasci et al., 2007). The cognitive destination image is investigated as a precedent of affective destination image from a conceptual perspective. The empirical evidence shows a significant association between the COG and AF (Gartner, 1994; Pike \& Ryan, 2004). In addition, scholars agree that there is a connection between the Image of the destination and the way visitors respond to a destination on cognition and affect-based (Stepchenkova \& Mills, 2010; Tasci et al., 2007). The DES consists of three distinctively different but connected hierarchically, known as a cognitive, affective, and conative destination image (Gartner, 1994). Agapito et al. (2013) and Basaran (2016) provided empirical evidence on the relationship between them.

Therefore, the correlation between the three main components of DES formation should keep SM in the tourism context (Gartner, 1994). Cognition comes first, as stated and observed in existing studies. Hence, consumers construct a COG with the information given on SM about the destination shared by DMO's, tourists, and residents. Then, feeling (AF), toward the tourist destination, comes next to cognition. The last is the action about the destination (CON), how individuals behave on the knowledge, and how individuals think of a destination. Finally, both cognitive and affective perceptions can affect actual behaviour (CON), all focused on SM information. Thus, the following hypothesis are developed:

Hypothesis 4: The COG in SM has a significant relationship with the AF. Hypothesis 5: The COG in SM has a significant relationship with the CON. Hypothesis 6: The AF in SM has a significant relationship with the CON.

\subsection{The mediating role of cognitive/affective image between content cues/non-content cues and conative destination image}

Gartner (1994) initially introduced the tourism destination image, saying that the concept includes three distinctly varied but hierarchically associated components (Stylidis et al., 2017; Tasci et al., 2007). Cognitive assessment implies beliefs or information about features of the destination (Papadimitriou et al., 2018). The AF signifies peoples' feelings and emotions about the destination (Hallmann et al., 2015). COG and AF is identified for interacting and communicating for many scholars, although others argue the opposite, the cognitive effect affective. The initial answer point to a destination is affective for a few scholars, which leads to successive steps in the stated destination's direction (Woosnam et al., 2020). There is empirical proof that high levels of desire result in more optimistic cognitive assessments of a destination's characteristic features (Rollero \& De Piccoli, 2010; Woosnam et al., 2020). Most scholars contend that a destination's affective appraisal differs mainly from their experience of a destination (Baloglu \& Mccleary, 1999). It showed that travellers initially evaluate a destination cognitively and then build emotions for destination (AF) (Woosnam et al., 2020).

Finally, the conative element is the action item, similar to behaviour (Gartner, 1994). Conative and the other two components are connected directly; The behaviour depends on the image created in cognitive and assessed in the affective process (Woosnam et al., 2020). Recent studies by Stylos et al. $(2016 ; 2017)$ have condemned this approach, arguing that conative destination lies at the same stage as cognitive and affective destination images. The research shows that all three aspects influence the intention of revisiting a tourist destination directly or 
indirectly without evaluating the mutual association between components.

Following Gartner's approach, (Agapito et al., 2013) said that tourism scholars in the literature have mostly linked the conative aspect with revisit or loyalty (for example (Chi \& Qu, 2008; Gnoth et al., 2009; Li et al., 2010). Loyalty/revisit or CON is a very complex factor for DMO's because it is less expansive, easier to use than to attract new visitors (Kanwel et al., 2019). In the investigation of meta-analysis on this area (Zhang et al., 2014), assessing the association among tourists' destination and future behavioural intentions (conceptualized as a CON). It has been concluded that COG and AFs often shaped CONs substantially (Woosnam et al., 2020), for example, the cognitive and affective elements affected the behavioural intentions (the CON) of tourists about the destination (e.g., suggest the destination or future revisit intention).

As suggested in these studies, the source of information associated with individual factors is likely to explain the development of the cognitive, affective, and CON and provide a tool for assessing users' behaviour concerning loyalty or future revisit intention (CON). Therefore, it is essential to analyze how Contextual IQ "CC, NCC," influence the CON through a mediator's COG and AF. Thus, the hypothesis is developed as follows:

Hypothesis 7: COG mediates the relationship between $\mathrm{CC}$ and $\mathrm{CON}$. Hypothesis 8: AF mediates the relationship between $\mathrm{CC}$ and $\mathrm{CON}$.

Hypothesis 9: COG mediates the relationship between NCC and CON.

Hypothesis 10: COG, AF mediate the relationship between Contextual IQ and CON

\section{Research methodology}

\subsection{Study design}

The primary data was quantitatively obtained by questionnaires. This method allows the researchers to obtain significant information in a shorter period from a wide range of populations with low cost. Questionnaires were designed to determine respondents' perception of IQ and DES formation components. Figure 1 illustrates the research model for this study.

Figure 1: Research model of the study

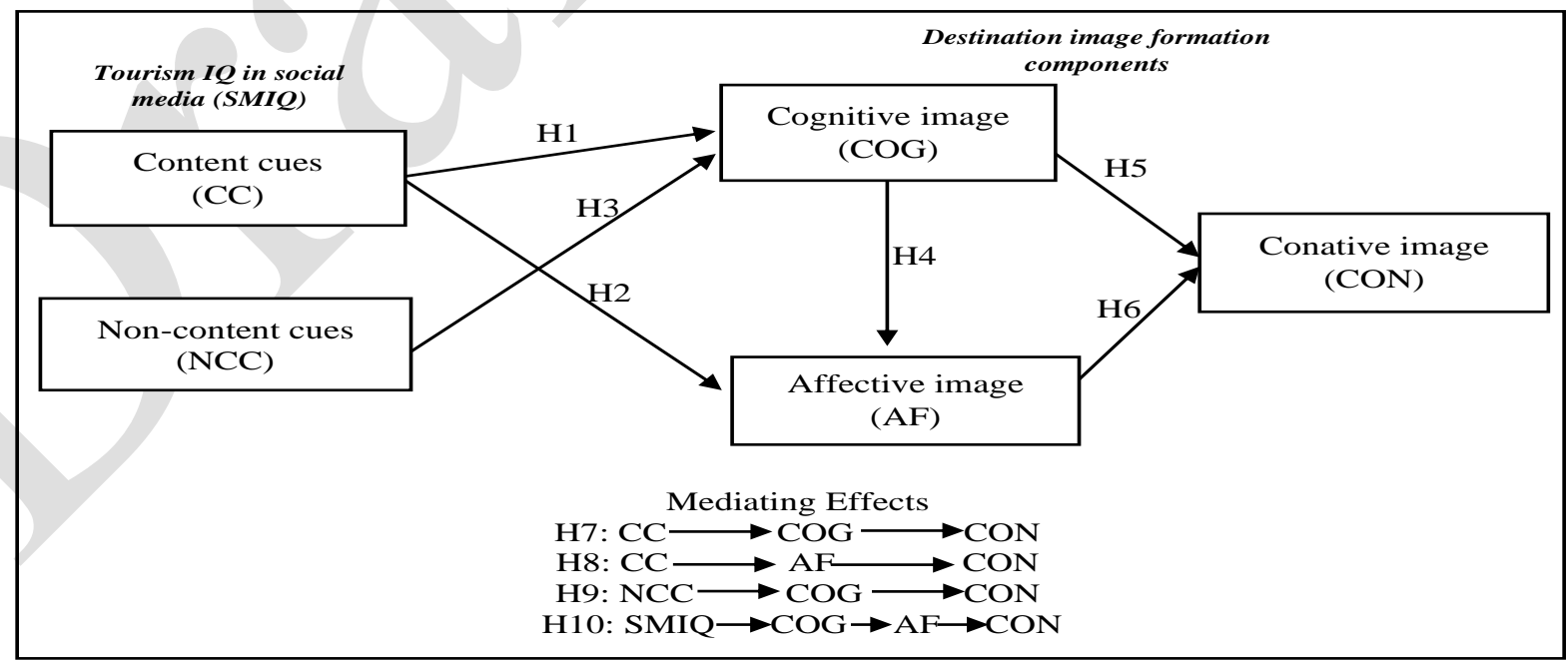

Content cues $=$ Relevancy + Timeliness + Completeness + Interestingness + Value-added

Non-content cues $=$ Quantity of information 


\subsection{Questionnaire development}

The questionnaire was adapted for this study from previously published studies. However, minimal changes were made to make them suitable for this study. The questionnaire primarily divided into several sections and one factor were explored in each section: CC consist of fifteen items which were adopted from (Kim et al., 2017; Lee et al., 2002), NCC comprised of three items taken from (Kim et al., 2017), COG consists of seven items from (Kim et al., 2017), AF consists of three items that were taken from (Kim et al., 2017; Stylos et al., 2016), and CON consists of three items which were adopted from (Kim et al., 2017). A 5-point Likert scale ranging from 1 (Strongly disagree) and 5 (Strongly agree) were adopted from previous studies. Besides, respondent demographic information was also included in one section, such as gender, marital status, age, education, income, and occupation.

\subsection{Data collection}

Empirical evidence for instrument validation and testing of the hypotheses were collected through a self-distributed questionnaire at various tourist destinations throughout the KP, Pakistan. We designed a questionnaire for SM users (Facebook, Instagram, Twitter) who obtain tourism-related information about KP, tourists' destinations. Sampling was carried out from July 2020 to August 2020 by distributing face-to-face questionnaires to tourists at a different tourist destination in KP. Our study's purpose was clarified to the visitors to increase participation, and questionnaires were given only to those who were willing to participate in this research survey. Five hundred questionnaires were distributed in total, and 446 were considered appropriately complete after the deletion of incomplete answers.

\section{Results and data analysis}

We used SPSS v.25 and AMOS to assess the data. Demographic information of respondents were defined by descriptive statistics (for results, see appendix-1). Correlation analysis, regression model, reliability and validity analysis, descriptive analysis, Confirmatory Factor Analysis (CFA), Structure Equation Modelling (SEM) were used to interpret the data.

\subsection{Descriptive statistic and correlation analysis}

The descriptive statistic, average variance extracted, correlation, composite reliability, and discriminant validity are shown in table 3 . The Standard Deviations (SD) value from 0.887 to 1.124 and the mean varied from 3.31 to 3.67 , respectively. The correlation values among $\mathrm{CC}$, NCC, Af, COG, and CON are substantial and positive, shown in table-1.

Table-1: Descriptive statistics, correlation, reliability, and validity analysis

\begin{tabular}{llllllllll}
\hline Factors & Means & SD & AVE & CR & 1 & 2 & 3 & 4 & 5 \\
\hline Content Cues & 3.46 & 0.887 & .505 & .845 & .837 & & & & \\
Non-content cues & 3.63 & 1.084 & .727 & .853 & $.560^{* *}$ & .890 & & & \\
Affective Image & 3.31 & 1.124 & .774 & .888 & $.700^{* *}$ & $.448^{* *}$ & .710 & & \\
Cognitive Image & 3.67 & 1.023 & .702 & .920 & $.593^{* *}$ & $.575^{* *}$ & $.567^{* *}$ & .850 & \\
Conative Image & 3.36 & 1.115 & .793 & .901 & $.698^{* *}$ & $.410^{* *}$ & $.641^{* *}$ & $.544^{* *}$ & .935 \\
\hline
\end{tabular}

Significance of correlation: $* * p<0.01$. CR: Composite reliability; AVE: Average variance extracted. Values on the diagonal (bolded) are the AVE's square root showing discriminant validity while the off diagonals are correlations. 


\subsection{Model fits}

We used various model fits in this study, for example, chi-square $x^{2}$, CFI, TLI, IFI, SRMR, and RMSEA. The value of TLI, CFI IFI must be greater than 0.90 (Jöreskog \& Sörbom, 1982). SRMR and RMSEA values not exceeding 0.08 (McNeish, 2018). As per (Bennett et al., 2017), for good model fit, $\mathrm{x}^{2} / \mathrm{df}$ must be less than 3 (Kanwel et al., 2019). The fit measurements are shown in table 2 . The values of this research are higher than the recommended standards (McNeish, 2018).

Table-2: Fit statistics

\begin{tabular}{ccc}
\hline Fit indicates & Model value & Reference value \\
\hline $\mathrm{X}^{2} / \mathrm{df}$ & 2.945 & $<5.00$ \\
$\mathrm{CFI}$ & 0.939 & $>0.90$ \\
$\mathrm{IFI}$ & 0.939 & $>0.90$ \\
$\mathrm{TLI}$ & 0.932 & $>0.90$ \\
$\mathrm{SRMR}$ & 0.092 & $>0.05$ \\
RMSEA & 0.066 & $<0.10$ \\
PCLOSE & .000 & $>0.05$ \\
& & $>$ NCP Saturated $(.000)$ \\
$\mathrm{NCP}$ & 610.728 & <NCP Independence $(10029.280)$ \\
& 2.078 & >FMIN Saturated $(.000)$ \\
FMIN & & <FMIN Independence $(23.326)$ \\
\hline
\end{tabular}

\subsection{Measurement model}

Based on the Wang \& Strong (1996) discussion IQ concept, (Chaiken, 1980) information processing Heuristic and Systematic model, and (Gartner, 1994) concept of the formation of DES from the perspective of the usage of social networks in the context of tourism, we proposed the DES formation and contextual IQ as our study model which were shown in Fig 1. our research goals to assess the association among the contextual dimension of IQ (CC and NCC) by (Wang \& Strong, 1996) three different components of the formation of DES proposed by (Gartner, 1994).

First, we evaluate the reliability and validity tests which are essential for the construct internal consistency. Therefore, we used Cronbach's alpha, a common technique for testing the item's internal consistency (Gefen et al., 2000; Manzoor et al., 2019). All variables' alpha values were ranged from $0.886-0.940$, which is higher than the recommended 0.70 , ensuring the inner consistency construct see table-3.

In addition, the internal constancy and validity were evaluated by composite reliability (CR), discriminant validity for each element to give further authenticity to the data shown in table- 2 . The CR of each component ranged from 0.845 to 0.920 , which exceeds the recommended criteria, CR> 70 (Hu \& Bentler, 1998). In contrast, each variable's AVE value extended from 0.505 to 0.793 , which should be higher than 0.50 (Fornell \& Larcker, 1981). Evaluating the discriminant validity of each value of the AVE square root was greater than all internal element correlation values (Shen et al., 2007). After analyzed the reliability and validity analysis, the Confirmatory Factor Analysis (CFA) was evaluated see table-3. 
Table-3: Confirmatory Factor Analysis (CFA) of the measurement model

\begin{tabular}{|c|c|c|c|c|}
\hline Construct factor & Items & EFA & CFA & Cronbach's alpha \\
\hline \multirow{11}{*}{ Content Cues } & $\mathrm{CC} 1$ & 0.717 & 0.71 & \multirow{11}{*}{0.930} \\
\hline & $\mathrm{CC} 2$ & 0.658 & 0.76 & \\
\hline & $\mathrm{CC} 3$ & 0.687 & 0.79 & \\
\hline & $\mathrm{CC} 4$ & 0.663 & 0.77 & \\
\hline & CC5 & 0.739 & 0.75 & \\
\hline & CC6 & 0.756 & 0.76 & \\
\hline & $\mathrm{CC} 7$ & 0.738 & 0.70 & \\
\hline & $\mathrm{CC} 8$ & 0.713 & 0.67 & \\
\hline & CC9 & 0.708 & 0.66 & \\
\hline & $\mathrm{CC} 10$ & 0.690 & 0.72 & \\
\hline & $\mathrm{CC} 11$ & 0.699 & 0.73 & \\
\hline \multirow{4}{*}{ Non-content Cues } & $\mathrm{NCC} 1$ & 0.811 & 0.81 & \multirow{5}{*}{0.886} \\
\hline & $\mathrm{NCC} 2$ & 0.887 & 0.89 & \\
\hline & NCC3 & 0.859 & 0.86 & \\
\hline & COG1 & 0.817 & 0.82 & \\
\hline \multirow{4}{*}{ Cognitive Image } & COG2 & 0.848 & 0.85 & \\
\hline & COG3 & 0.862 & 0.86 & \multirow{5}{*}{0.940} \\
\hline & COG4 & 0.863 & 0.86 & \\
\hline & COG5 & 0.852 & 0.85 & \\
\hline \multirow{5}{*}{ Affective Image } & COG6 & 0.807 & 0.81 & \\
\hline & COG7 & 0.815 & 0.82 & \\
\hline & $\mathrm{AF} 1$ & 0.837 & 0.84 & \multirow{3}{*}{0.914} \\
\hline & $\mathrm{AF} 2$ & 0.896 & 0.90 & \\
\hline & AF3 & 0.905 & 0.91 & \\
\hline \multirow{3}{*}{ Conative Image } & CON1 & 0.858 & 0.86 & \multirow{3}{*}{0.928} \\
\hline & $\mathrm{CON} 2$ & 0.914 & 0.91 & \\
\hline & $\mathrm{CON} 3$ & 0.900 & 0.90 & \\
\hline
\end{tabular}

\subsection{Hypothesis testing}

To test the hypothesis from 1-10 were analyzed and verified by applying regression weight $(\beta)$ result of the hypothesis are shown in (Table. 5, and Fig 2). First, we observed at the CC have a positive association with $\operatorname{COG}(\beta=0.68, \mathrm{t}=15.5, \mathrm{p}<0.01)$ and $\mathrm{AF}(\beta=0.88, \mathrm{t}=20.6, \mathrm{p}<$ $0.01)$ supporting $\mathrm{H} 1$ and $\mathrm{H} 2$. Hypothesis $3 \mathrm{NCC}$ is significantly related to $\mathrm{COG}(\beta=0.54, \mathrm{t}=$ $14.80, \mathrm{p}<0.01$ ) supporting H3. As we were expected that the COG was positive and significantly related with $\mathrm{AF}(\beta=0.51, \mathrm{t} 14.49, \mathrm{p}<0.01)$, AF was also a significant relationship with $\mathrm{CON}(\beta=0.65, \mathrm{t} 13.65, \mathrm{p}<0.01)$ are supporting $\mathrm{H} 4$ and $\mathrm{H} 5$, respectively. More ever the relation among COG and $\mathrm{CON}(\beta=0.61, \mathrm{t}=17.60, \mathrm{p}<0.01) \mathrm{H} 6$ is also supported.

We evaluated the mediation analysis, (Hayes, 2017) recommended using the Hayes, Andrew $F$ process for mediation to examine the indirect effect. Results for the mediation are shown in the table 4 and Figure 2, showing indirect effect of $\mathrm{CC} \longrightarrow \mathrm{AF} \longrightarrow \mathrm{CON}(\beta=0.273, \mathrm{p}<0.01)$, following the (Hayes, 2017) the indirect effect 0.273, 95\% CI boot, [LL 0.173, UL 0.374] does not turn a 0 in between indicating there is a mediation. Hence it is concluded that the mediation effect is statistically significant, indicating that $\mathrm{H} 7$ is supported. The outcome also indicates that relationship between $\mathrm{CC} \longrightarrow \mathrm{COG} \longrightarrow \mathrm{CON}$ was significant $(\beta=0.155, \mathrm{p}<0.01)$ with an indirect effect of $0.155,95 \%$ CI boot [ LL 0.082, UL 0.22] does not turn a 0 in between, representing there is a mediation, thus $\mathrm{H} 8$ is statistically significant and supported. 
Table-4: Regression coefficient ( $\beta$ ) for testing hypothesis 1-10

\begin{tabular}{|c|c|c|c|c|c|c|c|}
\hline Path & F-Stat & $\begin{array}{c}\mathrm{T}- \\
\text { values }\end{array}$ & S.E & $\beta$ & $\begin{array}{c}\text { LL95\% } \\
\text { CI }\end{array}$ & $\begin{array}{c}\text { UL95\% } \\
\text { CI }\end{array}$ & $\begin{array}{c}\text { P- } \\
\text { Value }\end{array}$ \\
\hline $\mathrm{CC} \longrightarrow \mathrm{AF}$ & 425.6 & 20.6 & .043 & .887 & & & *** \\
\hline $\mathrm{CC} \longrightarrow \mathrm{COG}$ & 240.2 & 15.5 & .044 & .684 & & & *** \\
\hline $\mathrm{NCC} \longrightarrow \mathrm{COG}$ & 290.0 & 14.80 & .037 & .542 & & & *** \\
\hline $\mathrm{COG} \longrightarrow \mathrm{AF}$ & 209.9 & 14.49 & 036 & .516 & & & $* * *$ \\
\hline $\mathrm{AF} \longrightarrow \mathrm{CON}$ & 186.4 & 13.65 & .037 & 659 & & & $* * *$ \\
\hline $\mathrm{COG} \longrightarrow \mathrm{CON}$ & 309.9 & 17.60 & .045 & .614 & & & $* * *$ \\
\hline $\mathrm{CC} \rightarrow \mathrm{AF} \rightarrow \mathrm{CON}$ & & 10.73 & .0511 & .2732 & 1739 & .3742 & *** \\
\hline $\mathrm{CC}-\cdots \mathrm{COG}^{--} \mathrm{CON}$ & & 14.06 & .0363 & .1551 & .0828 & .2272 & $* * *$ \\
\hline $\mathrm{NCC}^{-} \triangleright \mathrm{COG}^{-\rightarrow \mathrm{CON}}$ & & 9.476 & .0387 & .2818 & .2095 & .3612 & $* * *$ \\
\hline SMIQ $\gg \mathrm{AF} \rightarrow \mathrm{COG}$ & $\mathrm{CON}$ & 16.22 & .0574 & .4563 & .3440 & .5687 & **** \\
\hline
\end{tabular}

Note: $* * \mathrm{p}<0.01$. S.E: Standard error. $\mathrm{CC}=$ Content cues, $\mathrm{NCC}=$ Non-content cues, $\mathrm{AF}=$ Affective image, $\mathrm{COG}=$ Cognitive image $\mathrm{CON}=$ Conative Image, $\mathrm{SMIQ}=$ Social media information quality

For the NCC $\longrightarrow \mathrm{COG} \longrightarrow \mathrm{CON}$ was significant $(\beta=0.281, \mathrm{p}<0.01)$, with indirect effect of $0.281,95 \%$ CI boot [LL 0.2095, UL 0.361] and social media IQ $\longrightarrow \mathrm{AF} \longrightarrow \mathrm{COG} \longrightarrow \mathrm{CON}$ was significant $(\beta=0.456, p<0.01)$ with indirect effect of $0.456,95 \%$ CI boot, [LL 0.344 , UL 0.568 ] Hence it is concluded that the mediation effect is statistically significant indicating that $\mathrm{H} 9$ and $\mathrm{H} 10$ is supported.

Figure: 2 Result of the hypothesis

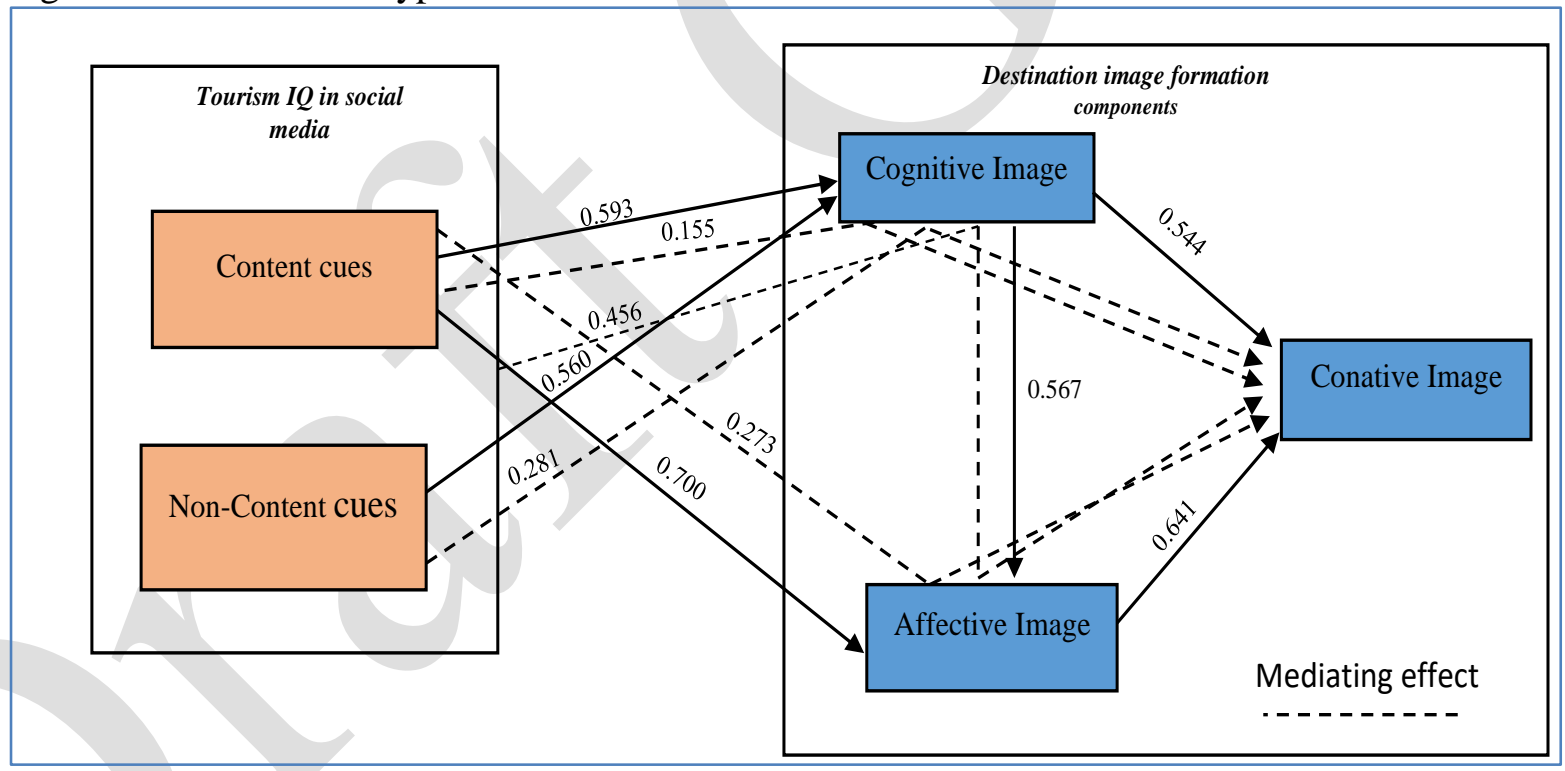

\section{Discussion and implications}

In this study, the association among the contextual quality of tourism information (CC and NCC) in SM and DES formation components (cognitive, affective, conative) is analyzed as well as this research also examines its association with the $\mathrm{CON}$ via the mediating role of the COG and AF. Our study's outcome validates the positive relationships among all the variables such as $\mathrm{CC}$, NCC, cognitive, affective, and CON. First, the "CC" of tourism IQ positively affect both the COG and AF. The Contents Cues = relevancy + completeness + value-added + timeliness + interestingness. It suggested that the extent to which travel information is posted 
on SM is essential to the tourist travel and other purposes; the information must be relevant to the tourist's travel, up to date, easy to understand, and complete to provide benefits to users.

Second, NCC have significantly associated with the COG. Another study conducted by (Kim et al., 2017) argues that the information amount did not positively associate with the COG. Their study survey chooses Chinese social media Sina Weibo allows limited words of 140 characters only. In our study, we focus on (Facebook, Instagram, and Twitter). According to our demographic survey outcome, $74 \%$ of tourists obtain tourism-related Information about the KP from Facebook because Facebook does not limit the number of characters. In addition, the proposed model (Gartner, 1994) for DES formation reconfirmed with our empirical study data analysis with Pakistani social media visitors (Facebook, Instagram, Twitter).

Furthermore, we examined the $\mathrm{CC}$ and $\mathrm{NCC}$ associated with $\mathrm{CON}$ via $\mathrm{COG}$ and AF's mediating role. Prior research linked the CON with "loyalty or revisit Intention"(Chi \& Qu, 2008; Li et al., 2010). The conative element is the action item, similar to behaviour (Gartner, 1994); the behaviour depends on the image created in the cognitive phase and assessed in the affective process. Our research outcome highlights that high-quality information should influence the individual behaviour $(\mathrm{CON})$ to share the positive word of mouth or suggest a destination to other people or revisit to destination in the future.

The outcome of this study also highlights that visitors' motives, such as the intention to revisit or intend to refer (conative destination image), are stronger when they discover more features of the destination attractions. It implied that the positive recognition of tourism attributes in KP (COG) could build pleasant feelings in visiting the KP tourist's destinations (AF), which lead to CON (loyalty/revisit). Our finding also reveals that cognitive destination image is closely linked to the affective destination image than conative destination image. In general, the indirectly method of creating cognitive-affective-conative destination image usually more concerned than the directly approach of making the cognitive-conative image because an individual develops distinct intent based on not just on cognitive dimension (perceptual) but also the affective dimension (feelings) for their behaviour (conative) in our study AF is more related with the CON (revisit/loyalty) than the COG. This outcome suggests that the various features of SM information on cognitive and affective destination image must be understood to deliver visitors with useful travel-related information on SM, leading to CON (future revisit intention/destination loyalty).

The tourism sector is a driving force for the growth of a country's economy and development. The emerging tourism industry can boost the economy's long-term viability, especially in revenue, GDP, job creation, and economic growth. The outcome from this research suggested several implications, such as this research adds to the literature and some managerial suggestion for KP DMO's. Firstly, this research empirically assesses the "CC and NCC" of tourism IQ in SM and its effect on the DES creation components. Our study results provide an empirical indication to investigate which aspect among $\mathrm{CC}$ and $\mathrm{NCC}$ is more associated with cognitive, affective.

Secondly, we examine the $\mathrm{CC}$ and NCC association with $\mathrm{CON}$ via $\mathrm{COG}$ and AF's mediating role. Prior research linked the CON with "loyalty or revisit intention" (Chi \& Qu, 2008; Kanwel et al., 2019; Li et al., 2010). The conative element is the action item, similar to behaviour (Gartner, 1994) the behaviour depends on the image created in the cognitive phase and assessed in the affective process. Our research outcome highlights that high-quality information should 
influence the individual behaviour (CON) to share the positive word of mouth or suggest a destination to other people or revisit to destination in the future. Finally, this research adds to the literature on contextual IQ in SM and its influence on DES creation components.

Moreover, this research was limited and organized in KP, Pakistan one of the country's tourism treasures. Our results provide strategic and operational insights, especially in SM, to collect destination information, which will help the destination marketing organization (DMO's) develop their marketing strategies to encourage more visitors by using SM to their destinations.

\section{Conclusion}

This study examines the association among the IQ in SM, precisely the contextual dimension of IQ classified as "CC, NCC" and DES components (e.g., cognitive, affective, conative). This research aims to provide helpful knowledge about the essential use of SM travel information that influences the destination's image and tourist behaviour. By examining the quality of the information in SM, we identified the impressive finding that both $\mathrm{CC}$ and NCC are quality factors of the tourism information, influencing the DES components. This study also examines the influence of "CC and NCC" of IQ in SM on the CON (Revisit/loyalty) through the mediating function of the COG and AF, which conclude that IQ has a significant impact on the CON. Thus, this research will extend the literature on SM in tourism and the quality of the information, more specifically, the contextual dimension of IQ. It enhances our awareness about the IQ and tourist DES forming process, offering factor insights to tourism marketers.

This research context was limited to KP Pakistan, and we focused on only a single dimension of IQ that is "contextual IQ," various region, a destination or whole country is highly recommended to verify hypothesized relationships by having other dimensions of IQ in the context of SM. This quantitative empirical research was designed without any qualitative study elements. This study can be extended using a qualitative approach; and true intention towards a DES can be even better explored. This research focuses only on the textual tourism information provided in SM. Further research is encouraged to add other dimensions apart from text-based information (e.g., photos and videos) in the research framework to acquire more insightful data.

\section{References}

Agapito, D., Oom do Valle, P., \& da Costa Mendes, J. (2013). The cognitive-affective-conative model of destination image: A confirmatory analysis. Journal of Travel \& Tourism Marketing, 30(5), 471-481. https://doi.org/10.1080/10548408.2013.803393

Arazy, O., \& Kopak, R. (2011). On the measurability of information quality. Journal of the American Society for Information Science and Technology, 62(1), 89-99. https://doi.org/10.1002/asi.21447

Baloglu, S., \& Mccleary, K. (1999). A Model of Destination Image Formation. Annals of Tourism Research, 26(4), 868-897. https://doi.org/10.1016/S0160-7383(99)00030-4

Basaran, U. (2016). Examining the Relationships of Cognitive, Affective, and Conative Destination Image: A Research on Safranbolu, Turkey. International Business Research, 9(5), 164-179. https://doi.org/10.5539/ibr.v9n5p164

Bennett, R. J., Taljaard, D. S., Olaithe, M., Brennan-Jones, C., \& Eikelboom, R. H. (2017). Evaluating random error in clinician-administered surveys: Theoretical 
considerations and clinical applications of interobserver reliability and agreement. American Journal of Audiology, 26(3), 191-201. https://doi.org/10.1044/2017_AJA$16-0100$

Berhanu, K., \& Raj, S. (2020). The trustworthiness of travel and tourism information sources of social media: perspectives of international tourists visiting Ethiopia. Heliyon, 6(3), e03439. https://doi.org/10.1016/j.heliyon.2020.e03439

Bosio, B., Haselwanter, S., \& Ceipek, M. (2018). The Utilization of Social Media Marketing in Destination Management Organizations. In D. Tipurić Darko Labaš (Ed.), 6th International OFEL Conference on Governance, Management and Entrepreneurship. New Business Models and Institutional Entrepreneurs: Leading Disruptive Change. April 13th - 14th, 2018, Dubrovnik, Croatia (pp. 249-268). Governance Research and Development Centre (CIRU). http://hdl.handle.net/10419/179996

Buhalis, D., \& Law, R. (2008). Progress in Information Technology and Tourism Management: 20 Years on and 10 Years After the Internet-The State of eTourism Research. Tourism Management, 29(4), 609-623. https://doi.org/10.1016/j.tourman.2008.01.005

Chaiken, S. (1980). Heuristic Versus Systematic Information Processing and the Use of Source Versus Message Cues in Persuasion. Journal of Personality and Social Psychology, 39(5), 752-766. https://doi.org/10.1037/0022-3514.39.5.752

Chaulagain, S., Wiitala, J., \& Fu, X. (2019). The impact of country image and destination image on US tourists' travel intention. Journal of Destination Marketing \& Management, 12, 1-11. https://doi.org/10.1016/j.jdmm.2019.01.005

Chen, S., \& Chaiken, S. (1999). The heuristic-systematic model in its broader context.

Chi, C., \& Qu, H. (2008). Examining the Structural Relationships of Destination Image, Tourist Satisfaction and Destination Loyalty: An Integrated Approach. Tourism Management, 29(4), 624-636. https://doi.org/10.1016/j.tourman.2007.06.007

Heras-Pedrosa, C. D. L., Millan-Celis, E., Iglesias-Sánchez, P. P., \& Jambrino-Maldonado, C. (2020). Importance of social media in the image formation of tourist destinations from the stakeholders' perspective. Sustainability, 12(10), 4092.https://doi.org/10.3390/su12104092

Eftekhari, M. H., Barzegar, Z., \& Isaai, M. T. (2010). Web 1.0 to web 3.0 evolution: reviewing the impacts on tourism development and opportunities. International Workshop on Human-Computer Interaction, Tourism and Cultural Heritage, 184-193.

Emamjome, F. F., Rabaa'i, A. A., Gable, G. G., \& Bandara, W. (2013). Information quality in social media: a conceptual model. Proceedings of the 17th Pacific Asia Conference on Information Systems (PACIS 2013). https://eprints.qut.edu.au/61822/13/61822.pdf

Fakeye, P., \& Crompton, J. (1991). Image Differences Between Prospective, First-Time, and Repeat Visitors to the Lower Rio Grande Valley. Journal of Travel Research, 30(2), 10-16. https://doi.org/10.1177/004728759103000202

Fatanti, M. N., \& Suyadnya, I. W. (2015). Beyond user gaze: How Instagram creates tourism destination brand? Procedia-Social and Behavioral Sciences, 211, 1089-1095. https://doi.org/10.1016/j.sbspro.2015.11.145

Fornell, C., \& Larcker, D.F. (1981). Evaluating Structural Equation Models with Unobservable Variables and Measurement Error. Journal of Marketing Research, 18(1), 39-50. https://doi.org/10.1177/002224378101800104

Fuchs, C., Hofkirchner, W., Schafranek, M., Raffl, C., Sandoval, M., \& Bichler, R. (2010). Theoretical foundations of the web: cognition, communication, and co-operation. 
Towards an understanding of Web 1.0, 2.0, 3.0. Future Internet, 2(1), 41-59. https://doi.org/10.3390/fi2010041

Gartner, W. (1994). Image Formation Process. Journal of Travel \& Tourism Marketing, 2(23), 191-216. https://doi.org/10.1300/J073v02n02_12

Gefen, D., Straub, D., \& Boudreau, M. C. (2000). Structural equation modeling and regression: Guidelines for research practice. Communications Association for Information System, 4 , $2-77$. https://aisel.aisnet.org/cgi/viewcontent.cgi?article $=2531 \&$ context=cais

Ghazali, R. M., \& Cai, L. (2014). Social media sites in destination image formation. In: Tourism Social Media: Transformations in Identity, Community and Culture, 18, 7386. https://doi.org/10.1108/S1571-5043(2013)0000018007

Gnoth, J., Andreu, L., Kozak, M., Bigné, J. E., \& Sánchez, I. (2009). The role of variety seeking in short and long run revisit intentions in holiday destinations. International Journal of Culture, Tourism and Hospitality Research, 3(2), 103-115. https://doi.org/10.1108/17506180910962113

Gretzel, U., Yuan, Y.-L., \& Fesenmaier, D. R. (2000). Preparing for the new economy: Advertising strategies and change in destination marketing organizations. Journal of Travel Research, 39(2), 146-156. https://doi.org/10.1177\%2F004728750003900204

Hallmann, K., Zehrer, A., \& Müller, S. (2015). Perceived destination image: An image model for a winter sports destination and its effect on intention to revisit. Journal of Travel Research, 54(1), 94-106. https://doi.org/10.1177\%2F0047287513513161

Hasan, M. A. (2015). Promotional activities in the strategic tourism development of lapland.

Hayes, A. F. (2017). Introduction to mediation, moderation, and conditional process analysis: A regression-based approach. Guilford publications.

Hays, S., Page, S. J., \& Buhalis, D. (2013). Social media as a destination marketing tool: its use by national tourism organisations. Current Issues in Tourism, 16(3), 211-239. https://doi.org/10.1080/13683500.2012.662215

Hernandez-Ortega, B., San Martin, H., Herrero, A., \& Franco, J. L. (2020). What, how and when? Exploring the influence of firm-generated content on popularity in a tourism destination context. Journal of Destination Marketing \& Management, 18, 100504. https://doi.org/10.1016/j.jdmm.2020.100504

Hu, L. T., \& Bentler, P. M. (1999). Cut-off criteria for fit indexes in covariance structure analysis: Conventional criteria versus new alternatives. Structural Equation Modelling: $\quad A \quad$ Multidisciplinary $\quad$ Journal, 6(1), $\quad$ 1-55. https://doi.org/10.1080/10705519909540118

Hudson, S., Roth, M., Madden, T., \& Hudson, R. (2015). The effects of social media on emotions, brand relationship quality, and word of mouth: An empirical study of music festival attendees. Tourism Management, 47, 68-76. https://doi.org/10.1016/j.tourman.2014.09.001

Hughes, M., Martin, S., Morgan, R., \& Robson, M. (2010). Realizing Product-Market Advantage in High-Technology International New Ventures: The Mediating Role of Ambidextrous Innovation. Journal of International Marketing, 18 (4), 1-21. https://doi.org/10.2307/25800808

Hunt, J. D. (1975). Image as a factor in tourism development. Journal of Travel Research, 13(3), 1-7. https://doi.org/10.1177\%2F004728757501300301

Jöreskog, K. G., \& Sörbom, D. (1982). Recent developments in structural equation modeling. Journal of Marketing Research, 19(4), 404-416. https://doi.org/10.1177\%2F002224378201900402 
Kahn, B. K., Strong, D. M., \& Wang, R. Y. (2002). Information quality benchmarks: product and service performance. Communications of the ACM, 45(4), 184-192. https://doi.org/10.1145/505248.506007

Kanwel, S., Lingqiang, Z., Asif, M., Hwang, J., Hussain, A., \& Jameel, A. (2019). The influence of destination image on tourist loyalty and intention to visit: Testing a multiple mediation approach. Sustainability, 11, 6401. https://doi.org/10.3390/su11226401

Kaplan, A., \& Haenlein, M. (2010). Users of the world, unite: The challenges and opportunities of social media. Business Horizons, 53(1), 59-68. https://doi.org/10.1016/j.bushor.2009.09.003

Kazak, L. (2016). The impact of social media on the tourism industry.

Kim, S.-E., Lee, K. Y., Shin, S., \& Yang, S.-B. (2017). Effects of tourism information quality in social media on destination image formation: The case of Sina Weibo. Information \& Management, 54(6), 687-702 https://doi.org/10.1016/j.im.2017.02.009

Kim, S., \& Yoon, Y. (2003). The hierarchical effects of affective and cognitive components on tourism destination image. Journal of Travel \& Tourism Marketing, 14(2), 1-22. https://doi.org/10.1300/J073v14n02_01

Lee, C.K., Lee, Y.-K., \& Lee, B. (2005). Korea's destination image formed by the 2002 world cup. Annals of Tourism Research, 32(4), 839-858. https://doi.org/10.1016/j.annals.2004.11.006

Lee, Y. W., Strong, D. M., Kahn, B. K., \& Wang, R. Y. (2002). AIMQ: a methodology for information quality assessment. Information \& Management, 40(2), 133-146. https://doi.org/10.1016/S0378-7206(02)00043-5

Leung, D., Law, R., Van Hoof, H., \& Buhalis, D. (2013). Social media in tourism and hospitality: A literature review. Journal of Travel \& Tourism Marketing, 30(1-2), 322. https://doi.org/10.1080/10548408.2013.750919

Li, J., Ali, F., \& Kim, W. (2015). Reexamination of the role of destination image in tourism: An updated literature review. E-Review of Tourism Research, 12(3/4), 191-209.

Li, M., Cai, L., Lehto, X., \& Huang, Z. (2010). A missing link in understanding revisit intention-The role of motivation and image. Journal of Travel \& Tourism Marketing, 27(4), 335-348. https://doi.org/10.1080/10548408.2010.481559

Manzoor, F., Wei, L., Bányai, T., Nurunnabi, M., \& Subhan, Q. (2019). An examination of sustainable HRM practices on job performance: An application of training as a moderator. Sustainability, 11(8), 2263. https://doi.org/10.3390/su11082263

Marine-Roig, E., \& Clavé, S. (2016). A detailed method for destination image analysis using user-generated content. Information Technology \& Tourism, 15(4), 341-364. https://doi.org/10.1007/s40558-015-0040-1

McNeish, D. (2018). Thanks coefficient alpha, we'll take it from here. Psychological Methods, 23(3), 412-433. https://psycnet.apa.org/doi/10.1037/met0000144

Minić N., N. A. T. C. J. (n.d.). The impact of Web 3.0 technologies on Tourism Information Systems.

Noti, E. (2013). Web 2.0 and the its influence in the tourism sector. European Scientific Journal, 9(20), 115-123. https://core.ac.uk/reader/328023780

Nunthiphatprueksa, A. (2017). The application of stimulus-organism-response paradigm: the role of social media in Thailand's destination image and behavioral intentions.

Papadimitriou, D., Kaplanidou, K., \& Apostolopoulou, A. (2018). Destination image components and word-of-mouth intentions in urban tourism: A multigroup approach. Journal of Hospitality \& Tourism Research, 42(4), 503-527. 
https://doi.org/10.1177\%2F1096348015584443

Pike, S. (2002). Destination image analysis: a review of 142 papers from 1973-2000. Tourism Management, 23, 541-549. https://doi.org/10.1016/S0261-5177(02)00005-5

Pike, S., \& Ryan, C. (2004). Destination Positioning Analysis through a Comparison of Cognitive, Affective, and Conative Perceptions. Journal of Travel Research, 42(4), 333-342 https://doi.org/10.1177/0047287504263029

Rollero, C., \& De Piccoli, N. (2010). Place attachment, identification and environment perception: An empirical study. Journal of Environmental Psychology, 30(2), 198205. https://doi.org/10.1016/j.jenvp.2009.12.003

San Martín, H., \& Del Bosque, I. A. R. (2008). Exploring the cognitive-affective nature of destination image and the role of psychological factors in its formation. Tourism Management, 29(2), 263-277. https://doi.org/10.1016/j.tourman.2007.03.012

Shen, N., Aggarwal, R., \& Shaffer, S. (2007). Extensions to OSPF for Advertising Optional Router Capabilities.

Söderlund, M., \& Rosengren, S. (2007). Receiving word-of-mouth from the service customer: An emotion-based effectiveness assessment. Journal of Retailing and Consumer Services, 14(2), 123-136. https://doi.org/10.1016/j.jretconser.2006.10.001

Stepchenkova, S., \& Mills, J. E. (2010). Destination image: A meta-analysis of 2000-2007 research. Journal of Hospitality Marketing \& Management, 19(6), 575-609. https://doi.org/10.1080/19368623.2010.493071

Stepchenkova, S., \& Morrison, A. M. (2008). Russia's destination image among American pleasure travelers: Revisiting Echtner and Ritchie. Tourism Management, 29, 548560. https://doi.org/10.1016/j.tourman.2007.06.003

Stylidis, D., Cherifi, B., \& Melewar, T. C. (2021). Exploring Czechs' and Greeks' mental associations of London: a tourist destination or a place to live in? Journal of $\begin{array}{lllll}\text { Destination Marketing \& } \quad \text { Management, } & 19, & 100530 .\end{array}$ https://doi.org/10.1016/j.jdmm.2020.100530

Stylidis, D., Shani, A., \& Belhassen, Y. (2017). Testing an integrated destination image model across residents and tourists. Tourism Management, 58, 184-195. https://doi.org/10.1016/j.tourman.2016.10.014

Stylos, N., Bellou, V., Andronikidis, A., \& Vassiliadis, C. A. (2017). Linking the dots among destination images, place attachment, and revisit intentions: A study among British and Russian tourists. Tourism Management, 60, 15-29. https://doi.org/10.1016/j.tourman.2016.11.006

Stylos, N., Vassiliadis, C. A., Bellou, V., \& Andronikidis, A. (2016). Destination images, holistic images and personal normative beliefs: Predictors of intention to revisit a destination. Tourism Management, 53, 40-60. https://doi.org/10.1016/j.tourman.2015.09.006

Tasci, A., \& Gartner, W. (2007). Destination image and its functional relationships. Journal of Travel Research, 45(4), 413-425. https://doi.org/10.1177/0047287507299569

Tasci, A., Gartner, W., \& Cavusgil, S. (2007). Conceptualization and operationalization of destination image. Journal of Hospitality \& Tourism Research, 31(2), 194-223. https://doi.org/10.1177/1096348006297290

Tham, A., Croy, G., \& Mair, J. (2013). Social media in destination choice: Distinctive electronic word-of-mouth dimensions. Journal of Travel \& Tourism Marketing, 30(1-2), 144-155. https://doi.org/10.1080/10548408.2013.751272

Usakli, A., Koç, B., \& Sönmez, S. (2017). How "social” are destinations? Examining European DMO social media usage. Journal of Destination Marketing \& Management, 
6(2),136-149 https://doi.org/10.1016/j.jdmm.2017.02.001

Wang, C., \& Hsu, M. (2010). The relationships of destination image, satisfaction, and behavioral intentions: An integrated model. Journal of Travel \& Tourism Marketing, 27(8), 829-843. https://doi.org/10.1080/10548408.2010.527249

Wang, R., \& Strong, D. (1996). Beyond accuracy: What data quality means to data consumers. Journal of Management Information Systems, 12(4), 5-33. https://doi.org/10.1080/07421222.1996.11518099

Wirth, W., Böcking, T., Karnowski, V., \& von Pape, T. (2007). Heuristic and systematic use of search engines. J. Computer-Mediated Communication, 12(3), 778-800. https://doi.org/10.1111/j.1083-6101.2007.00350.x

Woosnam, K. M., Stylidis, D., \& Ivkov, M. (2020). Explaining conative destination image through cognitive and affective destination image and emotional solidarity with residents. Journal of Sustainable Tourism, 28(6), 917-935. https://doi.org/10.1080/09669582.2019.1708920

Yang, S.-B. (2015). The role of online product reviews on information adoption of new product development professionals. Internet Research: Electronic Networking Applications and Policy, 25. https://doi.org/10.1108/IntR-11-2013-0238

Yüksel, A., \& Akgül, O. (2007). Postcards as affective image makers: An idle agent in destination marketing. Tourism Management, 28(3), 714-725. https://doi.org/10.1016/j.tourman.2006.04.026

Zeng, B., \& Gerritsen, R. (2014). What do we know about social media in tourism? A review. Tourism Management Perspectives, 10, 27-36. https://doi.org/10.1016/j.tmp.2014.01.001

Zhang, H., Fu, X., Cai, L. A., \& Lu, L. (2014). Destination image and tourist loyalty: A metaanalysis. Tourism Management, 40, 213-223. https://doi.org/10.1016/j.tourman.2013.06.006

Zhang, K. Z. K., Zhao, S. J., Cheung, C. M. K., \& Lee, M. K. O. (2014). Examining the influence of online reviews on consumers' decision-making: A heuristic-systematic model. Decision Support Systems, 67, 78-89. https://doi.org/10.1016/j.dss.2014.08.005 


\section{Appendices}

Appendix-1: Demographic characteristics of respondents

\begin{tabular}{|c|c|c|}
\hline Characteristic & & Percentage \\
\hline \multirow{3}{*}{ Gender } & Male & 70.6 \\
\hline & Female & 29.4 \\
\hline & Total & 100 \\
\hline \multirow{3}{*}{ Marital Status } & Single & 59.2 \\
\hline & Married & 40.8 \\
\hline & Total & 100 \\
\hline \multirow{6}{*}{ Age } & 20 year or below & 0.2 \\
\hline & $21-25$ & 45.1 \\
\hline & $26-30$ & 42.6 \\
\hline & $36-45$ & 9.2 \\
\hline & $46-55$ & 2.9 \\
\hline & Total & 100 \\
\hline \multirow{6}{*}{ Education } & Primary school & 0.4 \\
\hline & Secondary school & 2.5 \\
\hline & College/university & 14.3 \\
\hline & Undergraduate & 44.6 \\
\hline & Postgraduate & 38.1 \\
\hline & Total & 100 \\
\hline \multirow{7}{*}{ Monthly income PKR } & Less 10,000 & 25.3 \\
\hline & $10,000-19,999$ & 6.7 \\
\hline & $20,000-29,999$ & 10.3 \\
\hline & $30,000-39,000$ & 13.7 \\
\hline & $40,000-49,999$ & 24.7 \\
\hline & More than 50,000 & 19.3 \\
\hline & Total & 100 \\
\hline \multirow{6}{*}{ Occupation } & Government employee & 20.6 \\
\hline & Private sector & 38.8 \\
\hline & Student & 26.9 \\
\hline & Business owner & 10.3 \\
\hline & Housewife & 3.4 \\
\hline & Total & 100 \\
\hline \multirow{6}{*}{ Time spent on social media daily } & 1-2 hours & 23.8 \\
\hline & 3-4 hours & 40.4 \\
\hline & 5-6 hours & 30.5 \\
\hline & $7-8$ hours & 4.9 \\
\hline & More than 10 hours & 0.4 \\
\hline & Total & 100 \\
\hline \multirow{6}{*}{$\begin{array}{l}\text { Social media used for tourism } \\
\text { information }\end{array}$} & Facebook & 74.0 \\
\hline & Twitter & 5.6 \\
\hline & Instagram & 20.0 \\
\hline & YouTube & 0.2 \\
\hline & Others & 0.2 \\
\hline & Total & 100 \\
\hline
\end{tabular}


Appendix-2: Questionnaire

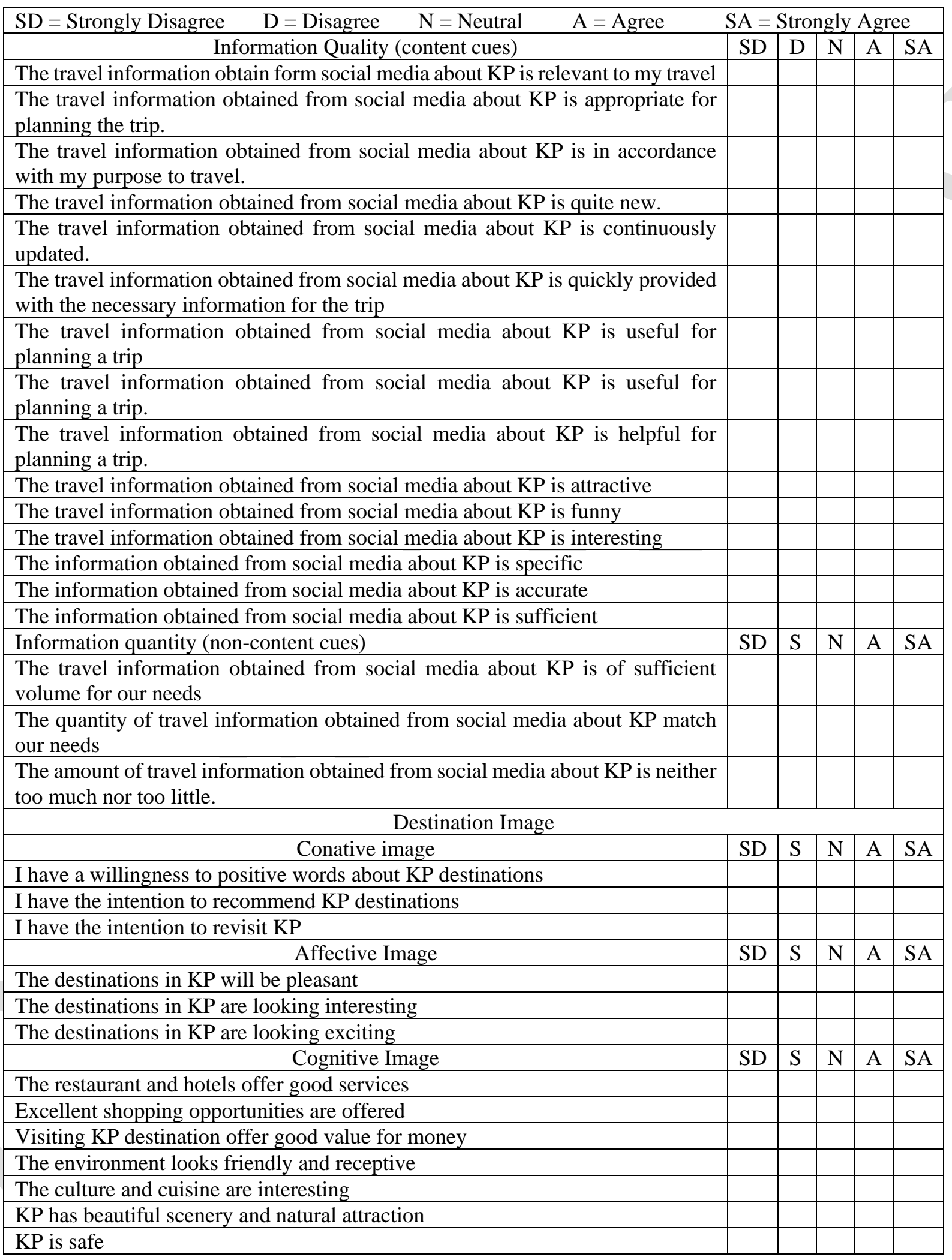

